Pacific Journal of Mathematics

CONVERGENCE OF EXTENDED BERNSTEIN POLYNOMIALS
IN THE COMPLEX PLANE 


\section{CONVERGENCE OF EXTENDED BERNSTEIN POLYNOMIALS IN THE COMPLEX PLANE}

J. J. Gergen, F. G. Dressel, and W. H. Purcell, Jr.

1. Introduction. Let $f(x)$ be defined on $[0,1]$. The following two theorems on the Bernstein polynomials corresponding to $f$,

$$
B_{n}(x ; f)=\sum_{\lambda=0}^{n} f\left(\frac{\lambda}{n}\right)\left(\begin{array}{c}
n \\
\lambda
\end{array}\right) x^{\lambda}(1-x)^{n-\lambda}, \quad n=1,2, \cdots,
$$

are well known.

Theorem I. If $f(x)$ is continuous on $[0,1]$, then $B_{n}(x ; f) \rightarrow f(x)$ as $n \rightarrow \infty$ uniformly on $[0,1]$.

THeOREM II. If $f(z), z=x+i y$, is analytic in the interior $E$ of the ellipse with foci at $z=0$ and $z=1$, then $B_{n}(z ; f) \rightarrow f(z)$ as $n \rightarrow \infty$ on $E$, this convergence being uniform on each closed subset of $E$.

The first of these results is due to S. Bernstein [1], the second to L. V. Kantorovitch [6] (See also [4], [7]).

For $f(x)$ defined on $[0, \infty)$ the functions

$$
P_{k}(x ; f)=e^{-k x} \sum_{\lambda=0}^{\infty} \frac{(k x)^{\lambda}}{\lambda !} f\left(\frac{\lambda}{k}\right), \quad 0<k,
$$

form a natural extension of the Bernstein polynomials, the terms of (1.2) corresponding to a Poisson distribution in much the same manner as the terms of (1.1) correspond to a binomial distribution. The functions (1.2) have been considered by Favard [5], Szász [9], and Butzer [3] for the real case. The results of Favard and Szász include the following analogue of Theorem I.

THEOREM III. If $f(x)$ is continuous on $[0, \infty)$, and if $f(x)=O\left(x^{A}\right)$. [Szász], or more generally, if $f(x)=O\left(e^{A x}\right)$ [Favard] as $x \rightarrow \infty$, where $A$ is a positive, real constant, then $P_{k}(x ; f) \rightarrow f(x)$ as $k \rightarrow \infty$ for $x$ on $[0, \infty)$, this convergence being uniform on each finite subinterval of $[0, \infty)$.

Received August 8, 1962, and in revised form January 2, 1963. This research was supported by the United States Air Force under Contract AF 49 (638)-892 and Grant AF AFOSR 61-51, monitored by the Air Force Office of Scientific Research of the Air Research and Development Command.

Presented by title to the Society, August 10, 1962, abstract $62 \mathrm{~T}-316$, under the title Extension of Bernstein polynomials for the complex plane. 
The order condition $f(x)=O\left(x^{A}\right)$ can be replaced by $O\left(e^{A x}\right)$ in Szasz' proof without difficulty through the application of the inequality

$$
\begin{aligned}
& \sum_{|(\lambda / u)-x| \geqq \delta} \frac{(t u x)^{\lambda}}{\lambda !} \leqq \frac{1}{\delta^{2} u^{2}} \sum_{\lambda=0}^{\infty} \frac{(\lambda-u x)^{2}(t u x)^{\lambda}}{\lambda !} \\
& =\frac{x}{\delta^{2} u}\left[u x(t-1)^{2}+t\right] e^{t u x},
\end{aligned}
$$

valid for $0<u, x, \delta, t$, in Szász' treatment [9, p. 240] of $S_{4}$.

In this paper our objective is to obtain an analogue of Theorem II. Our principal results are stated in $\S 2$ below. In our analysis we depend heavily upon the work [10] of Szász and Yeardley. Bohman [2] considers polynomials of the form $e^{-N z} \sum_{\lambda=0}^{n}\left((N z)^{\lambda} / \lambda !\right) f(\lambda / n), N=$ $N(n)$, in the complex plane, but there seems to be no existing treatment of the series (1.2) for the complex case.

2. Principal results Corresponding to the positive number $d$, let $p(d)$ denote the parabolic set $\left\{z|| z \mid<x+2 d^{2}\right\}$. We will say that a function $f(z)$ defined in $p(d)$ has property $B$ in $p(d)$ if there corresponds to each $b, 0<b<d$, a positive number $B(b)$ such that for $z \in p(b)$

$$
|f(z)| \leqq B(b) \exp \left\{\frac{1}{2} x-|x|^{1 / 2}\left[b^{2}-\frac{1}{2}(|z|-x)\right]^{1 / 2}\right\} .
$$

A collection of functions $\left\{f_{k}(x)\right\}_{0<k}$, each defined in $p(d)$, will be said to have property $B$ uniformly in $p(d)$ if there corresponds to each $b$, $0<b<d$, a positive number $B(b)$, independent of $k$, such that (2.1) holds for each $f_{k}$. Our principal theorem is then

THEOREM IV. Suppose that $f(z)$ is analytic and has property $B$ in $p(d)$, where $d$ is a positive number. Then the functions

$$
P_{k}(z ; f)=e^{-k z} \sum_{\lambda=0}^{\infty} \frac{(k z)^{\lambda}}{\lambda !} f\left(\frac{\lambda}{k}\right), \quad 0<k,
$$

satisfy the following four conditions. (1) $P_{k}(z ; f)$ is an entire function of $z$ for each $k$. (2) $P_{k}(z ; f) \rightarrow f(z)$ as $k \rightarrow \infty$ in $p(d)$.

The convergence in (2) is uniform on each compact subset of $p(d)$. (4) The functions $\left\{P_{k}\left(z / \chi_{k} ; f\right)\right\}_{0<k}$, where $\chi_{k}=\exp [1 /(2 k)]$, have property $B$ uniformly in $p(d)$.

We note the result of Pollard [8] and Szász and Yeardley [10] that, in order that a function $f(z)$ be analytic and have property $B$ in $p(d), 0<d$, it is necessary and sufficient that $f(z)$ possess a Laguerre series (of order 0 ), 


$$
f(z) \sim \sum_{n=0}^{\infty} a_{n} L_{n}(z), a_{n}=\int_{0}^{\infty} e^{-x} L_{n}(x) f(x) d x,
$$

which converges to it in $p(d)$. As a consequence of this result, the hypothesis in Theorem IV that $f(z)$ be analytic and have property $B$ in $p(d)$ can be replaced by the hypothesis that $f(z)$ possess a Laguerre series which converges to it in $p(d)$. The result of Szász and Yeardley [10] is valid as well for general Laguerre series.

3. Lemmas for Theorem IV. It is convenient to develop the proof of Theorem IV in lemmas. Unless the contrary is stated we assume $z$ arbitrary and $0<k$.

Lemma 1. If $f(z)$ is a polynomial, then $P_{k}(z ; f)$ is a polynomial of the same degree as $f$.

Proof. We can suppose $f \equiv z^{n}$, where $n$ is a nonnegative integer. We have

$$
e^{-z} \sum_{\lambda=0}^{\infty} \frac{z^{\lambda}}{\lambda !} \lambda^{n}=e^{-z}\left(z D_{z}\right)^{n} e^{z}=\sum_{j=0}^{n} c_{j}^{(n)} z^{j},
$$

where the $c_{j}^{(n)}$ are constants. We obtain then

$$
P_{k}(z ; f)=e^{-k z} \sum_{n=0}^{\infty} \frac{(k z)^{\lambda}}{\lambda !}\left(\frac{\lambda}{k}\right)^{n}=\frac{1}{k^{n}} \sum_{j=0}^{n} c_{j}^{(n)}(k z)^{j}
$$

and the lemma follows.

We may observe that $c_{n}^{(n)}=1$. It follows that $P_{k}(z ; f) \rightarrow z^{n}$ as $k \rightarrow \infty$ for every $z$, the convergence being uniform on each compact set. The same result then holds for any polynomial.

Lemma 2. Denote by $G_{k}^{(n)}(z)$ the polynomial

$$
G_{k}^{(n)}(z)=P_{k}\left(z ; L_{n}\right),
$$$$
n=0,1,2, \cdots,
$$

where $L_{n}$ is the nth Laguerre polynomial of order 0 . Then

$$
\left|G_{k}^{(n)}(z)\right| \leqq \exp \left(-k x+k \chi_{k}|z|\right), \quad n=1,2, \cdots,
$$

and

$$
\sum_{n=0}^{\infty} G_{k}^{(n)}(z) w^{n}=\frac{1}{1-w} \exp \left\{-k z+k z \exp \left[\frac{-w}{k(1-w)}\right]\right\},|w|<1
$$

Proof. The inequality (3.1) follows from the fact that [11, p. 162]

$$
\left|L_{n}(x)\right| \leqq \exp \left(\frac{1}{2} x\right), \quad 0 \leqq x, n=1,2, \cdots .
$$


For the Laguerre polynomials $L_{n}$ we have $[11$, p. 100]

$$
\sum_{n=0}^{\infty} L_{n}(z) w^{n}=\frac{1}{1-w} \exp \left(\frac{-z w}{1-w}\right), \quad|w|<1,
$$

from which we obtain

$$
\begin{aligned}
e^{-k z} \sum_{\lambda=0}^{\infty} \frac{(k z)^{\lambda}}{\lambda !} \sum_{n=0}^{\infty} L_{n}\left(\frac{\lambda}{k}\right) w^{n} & =\frac{e^{-k z}}{1-w} \sum_{\lambda=0}^{\infty} \frac{(k z)^{\lambda}}{\lambda !} \exp \left[\frac{-\lambda w}{k(1-w)}\right] \\
& =\frac{1}{1-w} \exp \left\{-k z+k z \exp \left[\frac{-w}{k(1-w)}\right]\right\} .
\end{aligned}
$$

For $z, k, w$, fixed, $|w|<1$, the double series on the left here is absolutely convergent. Interchanging the order of summation in this series we get (3.2).

LEMma 3. Let

$$
H_{k}(z, w)=\mathscr{R}\left\{-k z+k z \exp \left[\frac{-w}{k(1-w)}\right]\right\} .
$$

Then

$$
H_{k}(z, w) \leqq \chi_{k} r(|z|-r x) /\left(1-r^{2}\right), \quad|w|=r<1 .
$$

This is a principal lemma for the proof of Theorem IV. We show that

$$
H_{k}(z, w) \leqq \alpha r(|z|-r x) /\left(1-r^{2}\right), \quad|w|=r<1,
$$

where $\alpha=\alpha(r, k)=\exp \{r /[k(1+r)]\}$. This inequality is slightly stronger than (3.4). The proof is based on the representation (3.6), the use of which was suggested by the referee and results in a simpler proof than that originally submitted by the authors for (3.4).

Proof. The inequality (3.5) is trivial for $z=0$ or $w=0$. We assume then $|z|,|w|, k$ fixed with $z \neq 0,0<r<1$. We write

$$
\begin{array}{ll}
z=|z| e^{i \phi}, & \rho=r /\left(1-r^{2}\right), \quad e^{i \theta}=w(1-\bar{w}) /[r(1-w)], \\
a=1 / k, & \Phi=\phi-a \rho \sin \theta .
\end{array}
$$

We have then

$$
w /(1-w)=\rho\left(r+e^{i \theta}\right),
$$

and we find that (3.5) holds provided

$$
T(\theta, \phi)=(\alpha \alpha r \rho-1) \cos \phi+e^{-a \rho(r+\cos \theta)} \cos \Phi \leqq \alpha \alpha \rho
$$

for $|\theta|,|\phi| \leqq \pi$. Since $T$ is symmetric in the origin in the $(\theta, \phi)-$ 
plane, it is enough to show that (3.7) holds for $(\theta, \phi)$ in the rectangle $R: 0 \leqq \theta \leqq \pi,|\phi| \leqq \pi$. have

Suppose first that $1 \leqq \operatorname{a\alpha r} \rho$. Since $e^{t} \leqq 1+t e^{t}, 0 \leqq t$, we then

$$
T \leqq \operatorname{a\alpha r} \rho-1+\alpha \leqq \operatorname{a\alpha r} \rho+\operatorname{a\alpha r} /(1+r)=a \alpha \rho,
$$

which is (3.7) for this case.

Suppose then that $a \alpha r p<1$. Let $(\theta, \phi)$ denote a maximal point. of $T$ on $R$. We consider three possible cases

$$
\theta=0, \quad \theta=\pi, \quad 0<\theta<\pi .
$$

If $\theta=0$, then

$$
T=\left(\operatorname{a\alpha r} \rho-1+e^{-a r /(1-r)}\right) \cos \phi .
$$

If the coefficient of $\cos \phi$ here is nonnegative, we have immediately

$$
T \leqq \operatorname{a\alpha r} \rho \leqq \alpha \alpha \rho \text {. }
$$

If this coefficient is negative, we have

$$
\begin{aligned}
T & \leqq e^{a r /(1-r)}\left(e^{a r /(1-r)}-1\right)-a \alpha r \rho \\
& \leqq a r /(1-r)-a \alpha r \rho \leqq a \alpha \rho
\end{aligned}
$$

If $\theta=\pi$, then

$$
T=(\alpha \alpha r \rho-1+\alpha) \cos \phi \leqq \alpha \alpha \rho .
$$

Accordingly, to complete the proof it remains to consider the case: $0<\theta<\pi$.

At $(\theta, \phi)$ both first partial derivatives of $T$ vanish. Accordingly we obtain

$$
\begin{aligned}
& \sin (\theta+\Phi)=\sin \theta \cdot \cos \Phi+\cos \theta \sin \Phi=0, \\
& (\text { a } \alpha r \rho-1) \sin \phi+e^{-a \rho(r+\cos \theta)} \sin \Phi=0 .
\end{aligned}
$$

From these relations we then get

$$
\begin{aligned}
T \sin \theta & =(\alpha \alpha r \rho-1) \sin \theta \cos \phi+e^{-a \rho(r+\cos \theta)} \sin \theta \cos \Phi \\
& =(\alpha \alpha r \rho-1) \sin \theta \cos \phi-e^{-a \rho(r+\cos \theta)} \cos \theta \sin \Phi \\
& =(\alpha \alpha r \rho-1) \sin (\theta+\phi) .
\end{aligned}
$$

Now from (3.8) $\theta+\Phi=n \pi$, where $n=0, \pm 1, \cdots$. Thus $\theta+\phi=$ $\theta+\Phi+a \rho \sin \theta=n \pi+a \rho \sin \theta$, and

$$
T \sin \theta=(\alpha \alpha r \rho-1) \sin (n \pi+a \rho \sin \theta) .
$$

From (3.9) we get, since $\operatorname{a\alpha r} \rho<1$ and $0<\theta<\pi$, 


$$
T \sin \theta \leqq(1-\alpha \alpha r \rho) \alpha \rho \sin \theta \leqq \alpha \rho \sin \theta .
$$

The inequality (3.10) gives $T \leqq \alpha a \rho$, which completes the proof.

LEMma 4. Let $\alpha, \beta, \gamma$ be positive constants such that $\alpha \leqq \beta$. Put $u(t)=4 \alpha^{2} / t+t \beta^{2} /(4+t)$. Then

$I(\alpha, \beta, \gamma)=\int_{0}^{\infty} \frac{1}{1-e^{-t}} \frac{1}{t^{3 / 2}} \exp \left[-u(t)-\frac{4 \gamma^{2}}{t}\right] d t \leqq M_{1}(\gamma) \exp \left(\alpha^{2}-2 \alpha \beta\right)$, where

$$
M_{1}(\gamma)=e\left[2+\sqrt{\pi} /\left(16 \alpha^{3}\right)\right] /(e-1) .
$$

This lemma and the next two are closely related to results obtained by Szász and Yeardley [10]. Our proofs are somewhat different from theirs. The precise bound $M_{3}$ appearing in Lemma 6 does not occur in their article.

Proof. If $\alpha=\beta$, then $u(t)=\alpha^{2}+16 \alpha^{2} /[t(4+t)]>\alpha^{2}=2 \alpha \beta-\beta^{2}$ for $0<t$. If $\alpha<\beta$, then $u(t)$ has the minimum value $2 \alpha \beta-\alpha^{2}$ on this interval. Thus

$$
I \leqq \exp \left(\alpha^{2}-2 \alpha \beta\right) \int_{0}^{\infty} \frac{1}{1-e^{-t}} \frac{1}{t^{3 / 2}} \exp \left(-\frac{4 \gamma^{2}}{t}\right) d t .
$$

For $0<t \leqq 1$ we have $t(1-1 / e) \leqq 1-e^{-t}$, and for $1 \leqq t$ we have $1-1 / e \leqq 1-e^{-t}$. This gives

$$
\begin{aligned}
I \leqq & {[e /(e-1)] \exp \left(\alpha^{2}-2 \alpha \beta\right) } \\
& \times\left[\int_{0}^{1} t^{-5 / 2} \exp \left(-4 \alpha^{2} / t\right) d t+\int_{1}^{\infty} t^{-3 / 2} \exp \left(-4 \alpha^{2} / t\right) d t\right] .
\end{aligned}
$$

Now

$$
\begin{aligned}
& \int_{0}^{1} t^{-5 / 2} \exp \left(-4 \alpha^{2} / t\right) d t \leqq \int_{0}^{\infty} t^{-5 / 2} \exp \left(-4 \alpha^{2} / t\right) d t=\sqrt{\pi} /\left(16 \gamma^{3}\right) \\
& \int_{1}^{\infty} t^{-3 / 2} \exp \left(-4 \gamma^{2} / t\right) d t \leqq \int_{1}^{\infty} t^{-3 / 2} d t=2,
\end{aligned}
$$

and the lemma follows.

LEMMA 5. If $0<b<c$, and

$$
J(b, c, z)=\int_{0}^{\infty} \frac{1}{1-e^{-t}} \frac{1}{t^{3 / 2}} \exp \left[-\frac{4 c^{2}}{t}+\frac{2 e^{-t / 2}}{1-e^{-t}}\left(|z|-x e^{t / 2}\right)\right] d t,
$$




$$
J(b, c, z) \leqq M_{2}(b, c) \exp \left\{x-2|x|^{1 / 2}\left[b^{2}-\frac{1}{2}(|z|-x)\right]^{1 / 2}\right\}
$$

for $z \in p(b)$, where

$$
M_{2}(b, c)=e^{4 b^{2}} M_{1}\left(\left(c^{2}-b^{2}\right)^{3 / 2}\right) .
$$

Proof. Suppose $z \in p(b)$, so that $0<b^{2}+x$. From the inequalities $e^{-t / 2} /\left(1-e^{-t}\right) \leqq 1 / t, e^{-t / 2}\left(1-e^{-t / 2}\right) /\left(1-e^{-t}\right) \leqq 2 /(4+t)$, valid for $0<t$, we then obtain for $0<t$

$$
\begin{aligned}
\frac{2 e^{-t / 2}}{1-e^{-t}}\left(|z|-x e^{-t / 2}\right) & =\frac{2 e^{-t / 2}}{1-e^{-t}}\left[|z|-x+x\left(1-e^{-t / 2}\right)\right] \\
& \leqq \frac{2 e^{-t / 2}}{1-e^{-t}}\left[|z|-x+\left(x+b^{2}\right)\left(1-e^{-t / 2}\right)\right] \\
& \leqq 2(|z|-x) / t+4\left(x+b^{2}\right) /(4+t) \\
& =2(|z|-x) / t+x+b^{2}-t\left(x+b^{2}\right) /(4+t) .
\end{aligned}
$$

Thus

$$
\begin{aligned}
J \leqq e^{x+b^{2}} \int_{0}^{\infty} \frac{1}{1-e^{-t}} \frac{1}{t^{3 / 2}} \exp \left\{\frac{-4\left(c^{2}-b^{2}\right)}{t}\right. & -\frac{4}{t}\left[b^{2}-\frac{1}{2}(|z|-x)\right] \\
& \left.-\frac{t\left(x+b^{2}\right)}{4+t}\right\} d t .
\end{aligned}
$$

Since $b^{2}-\frac{1}{2}(|z|-x) \leqq x+b^{2}$, Lemma 4 is applicable. Applying this lemma we then get for $z \in p(b)$

$$
\begin{aligned}
J \leqq & e^{x+b^{2}} M_{1}\left(\left(c^{2}-b^{2}\right)^{3 / 2}\right) \\
& \cdot \exp \left\{b^{2}-\frac{1}{2}(|z|-x)-2\left(x+b^{2}\right)^{1 / 2}\left[b^{2}-\frac{1}{2}(|z|-x)\right]^{1 / 2}\right\} .
\end{aligned}
$$

Now $|x|^{1 / 2}-b \leqq\left(x+b^{2}\right)^{1 / 2}$ for $z \in p(b)$, and the lemma follows readily.

Lemma 6. Suppose $0<b<c$. Then

$$
\begin{aligned}
& \sum_{n=0}^{\infty}\left|G_{k}^{(n)}\left(z / \chi_{k}\right)\right|^{2} \exp (-4 c \sqrt{n}) \\
& \leqq M_{3}(b, c) \exp \left\{x-2|x|^{1 / 2}\left[b^{2}-\frac{1}{2}(|z|-x)\right]^{1 / 2}\right\}
\end{aligned}
$$

for $z \in p(b)$, where

$$
M_{3}(b, c)=(2 c \sqrt{\pi}) M_{2}(b, c) .
$$

Proof. Let $C_{r}, 0<r<1$, denote the circle of radius $r$ about the origin in the $w$-plane. Making use of Lemmas 2 and 3 and a classical 
integral formula we obtain

$$
\begin{aligned}
\sum_{n=0}^{\infty}\left|G_{k}^{(n)}(z)\right|^{2} r^{2 n} & =\frac{1}{2 \pi r} \int_{\sigma_{r}} \frac{1}{|1-w|^{2}}\left|\exp \left\{-k z+k z \exp \left[\frac{-w}{k(1-w)}\right]\right\}\right|^{2}|d w| \\
& =\frac{1}{2 \pi r} \int_{\sigma_{r}} \frac{1}{|1-w|^{2}} \exp \left[2 H_{k}(z ; w)\right]|d w| \\
& \leqq \frac{1}{2 \pi r} \int_{o_{r}} \frac{1}{|1-w|^{2}} \exp \left\{2 \chi_{k} r(z-r x) /\left(1-r^{2}\right)\right\}|d w| \\
& =\frac{1}{1-r^{2}} \exp \left[2 \chi_{k} r(|z|-r x) /\left(1-r^{2}\right)\right] .
\end{aligned}
$$

Thus, if $0<t$, then

$$
\begin{aligned}
& \sum_{n=0}^{\infty}\left|G_{k}^{(n)}\left(z / \chi_{k}\right)\right|^{2} e^{-n t} \\
& \quad \leqq\left[1 /\left(1-e^{-t}\right)\right] \exp \left\{2 e^{-t / 2}\left(|z|-x e^{-t / 2}\right) /\left(1-e^{-t}\right)\right\} .
\end{aligned}
$$

On the other hand,

$$
\exp (-4 c \sqrt{n})=(2 c / \sqrt{\pi}) \int_{0}^{\infty} t^{-3 / 2} \exp \left(-n t-4 c^{2} / t\right) d t
$$

Hence, applying Lemma 5, we get

$$
\begin{aligned}
\sum_{n=0}^{\infty}\left|G_{k}^{(n)}\left(z / \chi_{k}\right)\right|^{2} \exp (-4 c \sqrt{n}) \\
\quad=(2 c / \sqrt{\pi}) \sum_{n=0}^{\infty}\left|G_{k}^{(n)}\left(z / \chi_{k}\right)\right|^{2} \int_{0}^{\infty} t^{-3 / 2} \exp \left(-n t-4 c^{2} / t\right) d t \\
\quad=(2 c / \sqrt{\pi}) \int_{0}^{\infty} t^{-3 / 2} \exp \left(-\left(4 c^{2} / t\right)\left[\sum_{n=0}^{\infty}\left|G_{k}\left(z / \chi_{k}\right)\right|^{2} \exp (-n t)\right] d t\right) \\
\quad \leqq(2 c / \sqrt{\pi}) \int_{0}^{\infty} \frac{t^{-3 / 2}}{1-e^{-t}} \exp \left[\frac{-4 c^{2}}{t}+\frac{2 e^{-t / 2}}{1-e^{-t}}\left(|z|-x e^{-t / 2}\right)\right] d t \\
\quad \leqq(2 c / \sqrt{\pi}) M_{2}(b, c) \exp \left\{x-2|x|^{1 / 2}\left[b^{2}-\frac{1}{2}(|z|-x)\right]^{1 / 2}\right\}
\end{aligned}
$$

for $z \in p(b)$. This is the required inequality.

4. Proof of Theorem IV. Assume the hypotheses of Theorem: IV hold. We note first that under these hypotheses $f(x)$ satisfies

$$
|f(x)| \leqq A e^{x / 2}, \quad 0 \leqq x,
$$

for some positive constant $A$. It is seen then that the series in (2.2) converges for $z, k$ arbitrary, $0<k$. Thus conclusion (1) of Theorem IV holds.

Next, by the theorem of Pollard, and Szász and Yeardley noted in $\S 2$ above, the hypotheses of Theorem IV imply that $f$ can be repre-- 
sented in $p(d)$ by a convergent Laguerre series:

$$
f(z)=\sum_{n=0}^{\infty} a_{n} L_{n}(z), z \in p(d) ; \quad a_{n}=\int_{0}^{\infty} e^{-x} L_{n}(x) f(x) d x .
$$

From the convergence in $p(d)$ of the series (4.2) it follows that, if $\varepsilon$ is an arbitrary positive number, then

$$
\left|a_{n}\right| \leqq A_{\varepsilon} \exp [2 n(-d+\varepsilon)], \quad n=1,2, \cdots,
$$

for a suitably chosen positive constant $A_{\varepsilon}$. From (4.3) we obtain

$$
\sum_{n=0}^{\infty}\left|a_{n}\right|<\infty, M(c ; f)=\sum_{n=0}^{\infty}\left|a_{n}\right|^{2} \exp (4 c \sqrt{n})<\infty
$$

the latter provided $0<c<d$.

Now consider $P_{k}(z ; f)$. We have formally

$$
\begin{aligned}
P_{k}(z ; f) & =e^{-k z} \sum_{\lambda=0}^{\infty} \frac{(k z)^{\lambda}}{\lambda !} \sum_{n=0}^{\infty} a_{n} L_{n}(\lambda / k) \\
& =\sum_{n=0}^{\infty} a_{n}\left[e^{-k z} \sum_{\lambda=0}^{\infty} \frac{(k z)^{\lambda}}{\lambda !} L_{n}\left(\frac{\lambda}{k}\right)\right] \\
& =\sum_{n=0}^{\infty} a_{n} G_{k}^{(n)}(z) .
\end{aligned}
$$

Making use of (3.3) and the first inequality in (4.4) we see that the series in the first line of (4.5) converges absolutely for $z, k$ arbitrary, $0<k$. This justifies the formal manipulation in (4.5) and we accordingly have

$$
P_{k}(z ; f)=\sum_{n=0}^{\infty} a_{n} G_{k}^{(n)}(z)
$$

for $z, k$ arbitrary, $0<k$. From (4.6) we get

$$
\left|P_{k}(z ; f)\right|^{2} \leqq \sum_{n=0}^{\infty}\left|a_{n}\right|^{2} \exp (4 c \sqrt{n}) \sum_{n=0}^{\infty}\left|G_{k}^{(n)}(z)\right|^{2} \exp (-4 c \sqrt{n}) .
$$

Thus, by Lemma 6 , if $0<b<c<d$, then

$$
\left|P_{k}\left(z / \chi_{k} ; f\right)\right|^{2} \leqq M(c ; f) \cdot M_{3}(b, c) \cdot \exp \left\{x-2|x|^{1 / 2}\left[b^{2}-\frac{1}{2}(|z|-x)\right]^{1 / 2}\right\}
$$

for $z \in p(b)$. For a fixed $b, 0<b<d$, on taking $c=\frac{1}{2}(b+d)$, say, we find then that conclusion (4) holds with

$$
B(b)=\left[M(c ; f) M_{3}(b, c)\right]^{1 / 2}, \quad c=\frac{1}{2}(b+d) .
$$

It remains to consider conclusions (2) and (3). It is enough to show 
that, if $S$ is a compact subset of $p(d)$, then $P_{k}(z ; f) \rightarrow f(z), k \rightarrow \infty$, uniformly on $S$. For $0<b, 0<x_{0}$ let

$$
U\left(b, x_{0}\right)=\left\{z|| z \mid<x+2 b^{2}, x<x_{0}\right\} .
$$

Choose $b_{1}, b_{2}, b_{3} ; x_{1}, x_{2}, x_{3}$ such that $0<b_{1}<b_{2}<b_{3}<d, 0<x_{1}<x_{2}<x_{3}$. and $S \subset U\left(b_{1}, x_{1}\right)$. Making use of conclusion (4), we infer that there: exists a constant $M^{*}$ such that

$$
\left|P_{k}\left(z / \chi_{k} ; f\right)\right| \leqq M^{*}, z \in U\left(b_{3}, x_{3}\right) .
$$

Choose $k_{0}=\max \left\{\left[4 \cdot \ln \left(b_{3} / b_{2}\right)\right]^{-1},\left[2 \cdot \ln \left(x_{3} / x_{2}\right)\right]^{-1}\right\} . \quad$ Then for $k_{0}<k$ and $z \in U\left(b_{2}, x_{2}\right)$ we have $z \chi_{k} \in U\left(b_{3}, x_{3}\right)$. Thus

$$
\left|P_{k}(z ; f)\right|=\left|P_{k}\left(z \chi_{k} \mid \chi_{k} ; f\right)\right| \leqq M^{*}, k_{0}<k, z \in U\left(b_{2}, x_{2}\right) .
$$

Recalling (4.1), we have also, by Theorem III,

$$
P_{k}(x ; f) \rightarrow f(x), k \rightarrow \infty, 0<x<x_{2} .
$$

By an application of Vitali's theorem, $\left\{P_{k}(z ; f)\right\}_{k_{0}<k}$ converges uniformly on $U\left(b_{1}, x_{1}\right)$ to a function $F(z)$, analytic on $U\left(b_{1}, x_{1}\right)$. Since $f(z)$ is. analytic on $U\left(b_{1}, x_{1}\right)$ and $F(x)=f(x), 0<x<x_{1}$, it follows that $F(z)=$ $f(z)$ throughout $U\left(b_{1}, x_{1}\right)$, and the proof of complete.

\section{REFERENCES}

1. Serge Bernstein, Démonstration du théorème de Weierstrass, fondeé sur le calcul des: probabilitiés, Kharkov Universitet. Kharkovskoe Matematicheskoe Obshchestvo. Soobshchenia, 13 (series 2) (1912-1913) 1-2.

2. Harold Bohman, On approximation of continuous and analytic functions, (series 2) (1952-1954), 43-56.

3. P. L. Butzer, On the extensions of Bernstein polynomials to the infinite interval, Amer. Math. Soc. Proc., 5 (1954), 547-553.

4. P. L. Butzer, Summability of generalized Bernstein polynomials, I, Duke Mathematical Journal, 22 (1955) 617-623.

5. Jean Favard, Sur les multiplicateurs d'interpolation, Journal de Mathematiques. Pures et Appliquees, 23 (series 9), (1944), 219-247.

6. L. V. Kantorovitch, $O$ skhodimosti posledovatelnosti polinomov S. N. Bernstein za. predelami osnovnogo intervala, Akademiia nauk SSSR. Izvestiia. VII seriia. Otdelenie matematicheskikh $i$ estestvennykh nauk, (1931).

7. G. G. Lorentz, Bernstein polynomials, Toronto (1953).

8. Harry Pollard, Representation of an analytic function by a Laguerre series, Annals. of Math. 48 (series 2) (1947), 358-365.

9. Otto Szász, Generalization of S. Bernstein's polynomials to the infinite interval, Journal of Research of the National Bureau of Standards, 45 (1950), 239-245.

10. Otto Szász and Nelson Yeardley, The representation of an analytic function by general Laguerre series, Pacific J. Math. 8 (1958), 621-633.

11. Gabor Szegö, Orthogonal polynomials, Amer. Math. Soc. Colloq. Publ. 23 (1939). Revised edition, 1959. 


\section{PACIFIC JOURNAL OF MATHEMATICS}

\section{EDITORS}

RalPh S. Phillips

Stanford University

Stanford, California

M. G. Arsove

University of Washington

Seattle 5 , Washington
J. Dugundu

University of Southern California

Los Angeles 7, California

Lowell J. Paige

University of California

Los Angeles 24, California

\section{ASSOCIATE EDITORS}
E. F. BECKENBACH
D. DERRY
H. L. ROYDEN
E. G. STRAUS
T. M. CHERRY
M. OHTSUKA
E. SPANIER
F. WOLF

\section{SUPPORTING INSTITUTIONS}

\author{
UNIVERSITY OF BRITISH COLUMBIA \\ CALIFORNIA INSTITUTE OF TECHNOLOGY \\ UNIVERSITY OF CALIFORNIA \\ MONTANA STATE UNIVERSITY \\ UNIVERSITY OF NEVADA \\ NEW MEXICO STATE UNIVERSITY \\ OREGON STATE UNIVERSITY \\ UNIVERSITY OF OREGON \\ OSAKA UNIVERSITY \\ UNIVERSITY OF SOUTHERN CALIFORNIA
}

\author{
STANFORD UNIVERSITY \\ UNIVERSITY OF TOKYO \\ UNIVERSITY OF UTAH \\ WASHINGTON STATE UNIVERSITY \\ UNIVERSITY OF WASHINGTON \\ AMERICAN MATHEMATICAL SOCIETY \\ CALIFORNIA RESEARCH CORPORATION \\ SPACE TECHNOLOGY LABORATORIES \\ NAVAL ORDNANCE TEST STATION
}

Mathematical papers intended for publication in the Pacific Journal of Mathematrcs should be typewritten (double spaced), and the author should keep a complete copy. Manuscripts may be sent to any one of the four editors. All other communications to the editors should be addressed to the managing editor, L. J. Paige at the University of California, Los Angeles 24, California.

50 reprints per author of each article are furnished free of charge; additional copses may be obtained at cost in multiples of 50 .

The Pacific Journal of Mathematics is published quarterly, in March, June, September, and December. Effective with Volume 13 the price per volume (4 numbers) is $\$ 18.00$; single issues, $\$ 5.00$. Special price for current issues to individual faculty members of supporting institutions and to individual members of the American Mathematical Society: $\$ 8.00$ per volume; single issues $\$ 2.50$. Back numbers are available.

Subscriptions, orders for back numbers, and changes of address should be sent to Pacific Journal of Mathematics, 103 Highland Boulevard, Berkeley 8, California.

Printed at Kokusai Bunken Insatsusha (International Academic Printing Co., Ltd.), No. 6 , 2-chome, Fujimi-cho, Chiyoda-ku, Tokyo, Japan.

\section{PUBLISHED BY PACIFIC JOURNAL OF MATHEMATICS, A NON-PROFIT CORPORATION}

The Supporting Institutions listed above contribute to the cost of publication of this Journal, but they are not owners or publishers and have no responsibility for its content or policies. 


\section{Pacific Journal of Mathematics}

\section{Vol. 13, No. $4 \quad$ June, 1963}

Dallas O. Banks, Bounds for eigenvalues and generalized convexity ........... 1031

Jerrold William Bebernes, A subfunction approach to a boundary value problem for

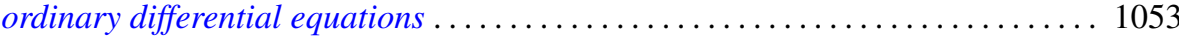

Woodrow Wilson Bledsoe and A. P. Morse, A topological measure construction . . . 1067

George Clements, Entropies of several sets of real valued functions . . . . . . . . . 1085

Sandra Barkdull Cleveland, Homomorphisms of non-commutative *-algebras . . . . . 1097

William John Andrew Culmer and William Ashton Harris, Convergent solutions of

ordinary linear homogeneous difference equations . . . . . . . . . . . . . . . 1111

Ralph DeMarr, Common fixed points for commuting contraction mappings . . . . . . 1139

James Robert Dorroh, Integral equations in normed abelian groups . . . . . . . . 1143

Adriano Mario Garsia, Entropy and singularity of infinite convolutions . . . . . . . 1159

J. J. Gergen, Francis G. Dressel and Wilbur Hallan Purcell, Jr., Convergence of extended Bernstein polynomials in the complex plane ................. 1171

Irving Leonard Glicksberg, A remark on analyticity of function algebras . . . . . . 1181

Charles John August Halberg, Jr., Semigroups of matrices defining linked operators

with different spectra ................................. 1187

Philip Hartman and Nelson Onuchic, On the asymptotic integration of ordinary

differential equations . . . . . . . . . . . . . . . . . . . . . . . . . . . . 1193

Isidore Heller, On a class of equivalent systems of linear inequalities . . . . . . . . . 1209

Joseph Hersch, The method of interior parallels applied to polygonal or multiply

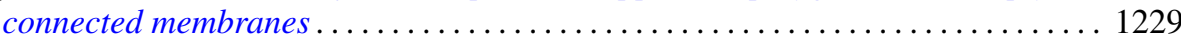

Hans F. Weinberger, An effectless cutting of a vibrating membrane . . . . . . . . . . 1239

Melvin F. Janowitz, Quantifiers and orthomodular lattices ....

Samuel Karlin and Albert Boris J. Novikoff, Generalized convex inequalities . .

Tilla Weinstein, Another conformal structure on immersed surfaces of negative

curvature.

Gregers Louis Krabbe, Spectral permanence of scalar operators

Shige Toshi Kuroda, Finite-dimensional perturbation and a representaion of

scattering operator.

Marvin David Marcus and Afton Herbert Cayford, Equality in certain

inequalities

Joseph Martin, A note on uncountably many disks .

Eugene Kay McLachlan, Extremal elements of the convex cone of semi-norms . . . . 1335

John W. Moon, An extension of Landau's theorem on tournaments . .

Louis Joel Mordell, On the integer solutions of $y(y+1)=x(x$

Kenneth Roy Mount, Some remarks on Fitting's invariants .....

Miroslav Novotný, Über Abbildungen von Mengen ............

Robert Dean Ryan, Conjugate functions in Orlicz spaces.

John Vincent Ryff, On the representation of doubly stochastic operators . . . . . . . . 1379

Donald Ray Sherbert, Banach algebras of Lipschitz functions .

James McLean Sloss, Reflection of biharmonic functions across analytic boundary

conditions with examples.

L. Bruce Treybig, Concerning homogeneity in totally ordered, connected topological space....

John Wermer, The space of real parts of a function algebra...

James Juei-Chin Yeh, Orthogonal developments of functionals and related theorems

in the Wiener space of functions of two variables......... 